\title{
$\widehat{A}$ Madridge \\ madridge Journal of Case Reports and Studies \\ Interconnecting Scientific World
}

Mini Review

Open Access

\section{Replication of SARS CoV2 in Pancreatic Cells via ACE2 Cell Surface Receptors}

\author{
Kaiser Jamil ${ }^{1 *}$, Kavita Kumari Kakarala ${ }^{2}$ and Asimuddin $\mathbf{M}^{3}$ \\ Genetics Department, Bhagwan Mahavir Medical Research Centre 10-1-1, Mahavir Marg, A C Guards, Hyderabad, TS, India
}

\section{Article Info}

*Corresponding author:
Kaiser Jamil
Head of Genetics Department
Bhagwan Mahavir Medical Research Centre
Hyderabad
India
E-mail: kj.bmmrc@gmail.com

Received: October 16, 2021

Accepted: November 18, 2021

Published: November 25, 2021

Citation: Jamil K, Kakarala KK, Asimuddin M. Replication of SARS CoV2 in Pancreatic Cells via ACE2 Cell Surface Receptors. Madridge J Case Rep Stud. 2021; 5(1): 182-186.

doi: $10.18689 /$ mjcrs-1000148

Copyright: $(2021$ The Author(s). This work is licensed under a Creative Commons Attribution 4.0 International License, which permits unrestricted use, distribution, and reproduction in any medium, provided the original work is properly cited.

Published by Madridge Publishers

\begin{abstract}
Earlier studies have reported that Diabetes mellitus (DM) increases the complications of Severe acute respiratory syndrome coronavirus 2 (SARS CoV2) or Coronavirus disease 2019 (COVID19), and patients are more likely to experience severe symptoms that could lead to mortality. One hypothesis states that hyperglycemic conditions facilitate the virus entry into the cell since the virus and the Angiotensin-Converting Enzyme 2 (ACE2) both require glucose for their function. However the exact interaction between the two has not been clearly defined from the cell biology point of view. The underlying mechanism for this differential effect in individuals with and without diabetes is not clearly understood. The reason for this could be due to the preexisting pathological pathways in patients with poorly controlled diabetes, which increases the risk of infectivity and are responsible for the higher levels of tissue injury and death in patients with diabetes [1]. However in this article we have focused mainly on COVID-19 induced diabetes as this area has lacuna. The diabetes specialists point out that many key metabolic tissues in the body, including pancreatic beta cells (b-cell) in the pancreas, adipose (fat storage) tissue, the small intestine, and kidneys, contain ACE2 receptors. They believe that when these viruses bind to ACE2 receptors, they may trigger changes in glucose metabolism that worsen preexisting diabetes or cause the condition to develop diabetes for the first time.
\end{abstract}

Keywords: SARS CoV2; Diabetes; ACE2 receptors; Pancreas beta cells; Glucose metabolism.

\section{Introduction}

Type 2 diabetes mellitus (T2DM) is a metabolic disorder that currently affects more than 400 million worldwide and is projected to cause 552 million cases by the year 2030 [2]. Whereas the acute respiratory effects of severe acute respiratory syndrome coronavirus 2 (SARS-CoV-2) infections are apparent, the long-term consequences of the virus remain unknown $[3,4]$. Since the initial months of the pandemic, there has been much discussion of the relationship between SARS-CoV-2 and diabetes. Scientists have reported that there is a bidirectional relationship between Covid-19 and diabetes. On the one hand, diabetes is associated with an increased risk of severe Covid-19. On the other hand, new-onset diabetes and severe metabolic complications of preexisting diabetes, including diabetic ketoacidosis and hyperosmolarity for which exceptionally high doses of insulin are warranted, have been observed in patients with Covid-19 [5]. These manifestations of diabetes pose challenges in clinical management and suggest a complex pathophysiology of Covid-19-related diabetes. However, what remains unclear at present is whether infection with SARS-CoV-2 might itself precipitate newonset diabetes, or possibly predispose patients to the development of diabetes in the longer term. Regardless, a key aspect of either exacerbation or initiation of diabetes is 
the health and viability of pancreatic $\beta$ cells, the relatively small number of which are responsible for the secretion of insulin. The loss or dysfunction of $\beta$ cells is considered an underlying feature of all forms of diabetes, and therefore the potential that SARS-CoV-2 might infect these cells becomes salient with respect to both short- and long-term sequela of COVID-19.

\section{Evidence of ACE2 and TMPRSS2 on pancreatic beta cells}

Ex-vivo studies have demonstrated the vulnerability of $\beta$-cells to SARS-CoV-2 which showed the replication of viral particles in pancreatic cells with robust expression of viral proteins such as viral spike $(\mathrm{S})$ and nucleocapsid $(\mathrm{N})$ protein and the co-expression of two essential docking proteins Angiotensin-Converting Enzyme 2 (ACE2) and Transmembrane protease serine 2 (TMPRSS2) [6]. In human, ACE2 and TMPRSS2 are the two main entry receptors for the SARSCoV-2 transmission. Data from recent studies have shown that in COVID-19, the cell surface ACE2 receptor of the respiratory tract's target cells to help the SARS-CoV-2 viral binding and infection of the host cell, the transmembrane TMPRSS2 cleaved the viral spike protein and supported virion entry into the cell $[7,8]$. Although the study on SARS-CoV-1 show the presence of the ACE2 receptor on the pancreatic $\beta$-cells, which assist viral binding and infection, leading to the damage of the $\beta$-cells and insulin insufficiency that causes hyperglycemia in diabetic patients [9]. These results were confirmed by blocking the expression of viral proteins activity of SARS-CoV-2 with effective concentration of $5-\mu \mathrm{M}$ remdesivir for COVID-19 entry [10]. On the other hand, transcriptional studies in human pancreatic islets infected with SARS-CoV-2 indicated the up-regulation of several genes linked to IFN-stimulated genes and down-regulation of genes linked to $\beta$-cell function [11]. However, in the absence of functional data, it has remained speculative if levels of these entry factors correlate with the ability of the virus to infect $\beta$ cells.

Studies also show that SARS-CoV-2 can gain entry into endothelial cells via the endothelial cell surface ACE2 receptors [12-14]. Another study reported a different mechanism for impaired endothelial function. Pericytes were identified as a part of viral entry rather than endothelial cells contributing to a leaky endothelial barrier $[15,16]$. SARSCoV-2 particles and host inflammatory cells were present within the endothelial cells, indicative of impaired integrity of the vasculature and were related to more ICU admissions among COVID-19 patients [17-19]. These patients presented with higher levels of D-dimer, von Willebrand factor (VWF) and soluble P-selectin, and factor VIII activity and manifested venous thromboembolism and microvascular lung thrombosis $[20,21]$. Cumulative evidence suggests that a glycolytic trait can influence the course of the disease by promoting viral tropism and negatively modulate the immune response and functional integrity of tissues, including endothelium [18]. Recent investigation on the mechanism of association between Covid-19 and diabetes has proved that proinflammatory cytokines, increase ACE2 expression in the $\beta$-cell line EndoC- $\beta \mathrm{H} 1$ and in primary human pancreatic islets. Interestingly, preferential expression of ACE2 isoforms in human $\beta$ cells and ACE2 receptor upregulation induced by proinflammatory conditions was also reported, thereby establishing a link between inflammation and ACE2 expression levels in islet $\beta$ cells [22-24].

\section{Incidence of People developing diabetes after having COVID-19}

Earlier lab studies as shown above have suggested that SARS-CoV-2 can infect human beta cells [25]. They also showed that this dangerous virus can replicate in these insulin-producing beta cells, to make more copies of it and spread to other cells $[15,23]$. Based on current clinical data, it appears that SARS-CoV-2 may trigger severe diabetic ketoacidosis (DKA) in individuals with new-onset type 1 diabetes [26,27]. However, up to now, there is no unambiguous evidence that SARS-CoV-2 induces type 1 diabetes $[28,29]$. SARS-CoV-2 infection can affect multi-organ systems, and this proportionally correlated with the expression and distribution pattern of ACE2 receptors in various organs. Emerging studies supported the viral tropism to both exocrine and endocrine cells of the pancreas and demonstrated modification in the pancreas' morphological, translational, and functional aspects, ultimately impairing insulin secretion [30-32].

The question remains whether SARS-CoV-2 infection can destroy pancreatic microvasculature/ductal cells by binding on ACE2 receptor, expressed in Human pancreatic -cells leading to diabetes. It was reported that the SARS-CoV-2 receptor, ACE2, and related entry factors (TMPRSS2, NRP1, and TRFC) are expressed in $\beta$ cells, with selectively high expression of NRP1. Further, SARS-CoV-2 infects human pancreatic $\beta$ cells in patients who succumbed to COVID-19 and selectively infects human islet $\beta$ cells in vitro. SARS-CoV- 2 infection attenuated pancreatic insulin levels and secretion and induces $\beta$ cell apoptosis, each rescued by NRP1 inhibition that observed in type 1 diabetes (T1D). This study showed that SARS-CoV-2 can directly induce $\beta$ cell killing [33]. Exacerbated inflammation and elevated blood glucose is a common factor between diabetes and Covid-19, also a glycolated trait was reported in monocytes of SARS-CoV-2 infected patients. Further, it was demonstrated that patients showed increased cytokine levels with increase in glucose levels as immune response. Studies have observed that high serum levels of IL-6, IL-10, IL-4, IL-2 and TNF alpha were significantly higher in Diabetic patients. Such parallels were seen in COVID-19 patients and it is referred as "cytokine strom" - as the immune response. The question still remains whether such events could be due to underlying diabetic conditions. Hence more research is needed to distinguish between preexisting diabetic conditions and COVID-19 induced diabetes; this would help in designing the strategies for treatment.

The studies of Tang et al., [34] also demonstrate the presence of entry factors ACE2 and NRP1 in human $\beta$ cells and show that $\beta$ cells can be infected by SARS-CoV- 2 in vitro. 
Additionally, these authors show that reduced insulin levels in infected cells are accompanied by increases in glucagon (a characteristic of $\alpha$ cell) and trypsin1 (a characteristic of exocrine cells). This phenotypicalteration, or transdifferentiation, appears to be mediated by the activation of the kinase PKR and its inhibition of the translation factor elF2 $\alpha$-events collectively referred to as the integrated stress response. An inhibitor of this response, trans-ISRIB, attenuated transdifferention and restored insulin production in $\beta$ cells following infection $[35,36]$. However, it is important to conduct more studies to understand how the coronavirus reaches the pancreas and what role the immune system might play not only in the pancreatic damage process but also in the pathophysiology of insulin resistance.

\section{Discussion}

Given the very short history of human infection with SARSCoV-2, an understanding of how Covid-19-related diabetes develops, the natural history of this disease, and appropriate management will be helpful. The study of Covid-19-related diabetes may also uncover novel mechanisms of disease [37]. In view of the emerging research in recent times, the hypothesis of a potential diabetogenic effect of COVID-19 becomes recognized. But it is yet to be determined whether the alteration of glucose metabolism occurs with the onset of COVID-19 or due to underlying preexisting diabetic conditions. What is clear so far is that the pancreatic beta cells may get infected by corona virus and subsequently interfere with insulin- producing beta cells? Beta cells and other types cell types in the pancrease express ACE2 receptor protein, the TMPRSS2 enzyme protein and neuropilin-1 (NRP-1) all of which provide the entry point of SARS CoV-2 in humans [38].

The Chen team and Jackson team reported signs of coronavirus in both insulin-producing beta cells and other cell types in the autopsied pancreatic tissue. The team also reported death of those cells upon infection by SARS CoV2(https://directorsblog.nih.gov/2021/06/08/how-covid-19can-lead-to-diabetes/)

\section{Beyond the question of impaired insulin secretion}

Very few authors discuss the relationship of-can covid-19 causes Diabetes, one suggestion by Accili (2021) [30] documents that Can SARS-CoV-2, the pathogenic virus underlying COVID-19, can cause diabetes, among its many effects?. But attribution beyond the occasional coincidence remains difficult. The hyperglycaemia in COVID-19 has multiple causes and probably involves impaired glucose disposal as well as diminished insulin secretion [39]. Any inflammatory state can cause insulin resistance and increase hepatic glucose production through increased counterregulatory hormones, release of cytokines and lipids, and direct hepatocyte injury. In addition, inflammation can impair peripheral glucose uptake through immobilization, muscle wasting, cytokines and fluid/electrolyte abnormalities that alter membrane permeability $[40,41]$. Obesity is another important risk factor for the comorbidities mentioned above, and local inflammation of adipose tissue can serve as a potential unifying driver of impaired glucose metabolism, inflammation and immune responses. In addition, as steroid use to treat COVID-19 has gone mainstream, the recovery of $\beta$-cell function is delayed or blunted [42]. Finally, we would expect ACE2 expression in $\beta$ cells to be a key feature necessary for the virus to inflict their specific loss and promote diabetes development directly-an observation not reported earlier.

\section{Conclusion}

The corona virus-SARS COV-2 which causes the disease COVID-19 gains entry into the humans through the nostrils and enters by binding to its receptor (angiotensin-converting enzyme 2) ACE2 receptors amply present on the lungs, but we know that the presence of this receptor is not limited to the lungs only as this receptor is also expressed in key metabolic organs and tissues, including pancreatic beta cells, adipose tissue, the small intestine, and the kidneys. However as demonstrated by few authors it is plausible that SARS-CoV-2 may cause pleiotropic alterations of glucose metabolism that could complicate the pathophysiology of preexisting diabetes or lead to new mechanisms of disease. These observations support the hypothesis of a potential diabetogenic effect of SARS CoV-2, beyond the well-recognized stress response associated with severe illness. It is still intriguing to know whether the alterations of glucose metabolism that occur due to a sudden onset in severe Covid-19 can persist or remit when the infection resolves is unclear. The question may remain as to how frequent is the phenomenon of new-onset diabetes, and is it classic type 1 or type 2 diabetes or a new type of diabetes? Do these patients remain at higher risk for diabetes or diabetic ketoacidosis? In patients with preexisting diabetes, does Covid-19 change the underlying pathophysiology and the natural history of the disease? [43] This article is an attempt to answering these questions in order to find better strategies for treatment and clinical care, follow-up, and monitoring of affected patients.

"To address these issues, an international group of leading diabetes researchers participating in the CoviDIAB Project has established a global registry of patients with Covid-19-related diabetes (covidiab.e-dendrite.com. Opens in new tab). The goal of the registry is to establish the extent and phenotype of new-onset diabetes that is defined by hyperglycemia, confirmed Covid-19, a negative history of diabetes, and a history of a normal glycated hemoglobin level." Above all, this work provides yet another reminder of the importance of protecting individuals from COVID-19 by vaccines.

Conflict of Interest: none declared

\section{Acknowledgements}

I thank all the Researchers from whom I learnt that COVID-19 can induce sharp rise glucose levels in non diabetic patients, Further in my own Observations I have recorded several non-diabetic patients when infected with the SARS CoV-2 virus showing diabetogenic effects of COVID-19. 
I thank the Chairman of MHRC and Research Director (Dr.P.P. Reddy) of Bhagwan Mahavir medical Research centre for their encouragement.

\section{References}

1. Kaiser Jamil, Zamin Dar, M. Asimuddin, Nadeem Fatima and Naga Chaitanya. Pharmacogenomic Studies of ACE and ARB Inhibitor Drug Therapy in Type-II Diabetic Nephropathy (T2DN) Patients with GSTT1 and GSTM1 Gene Polymorphisms. Asian Journal of Emerging Research. 2020; 2(2): 90-99. doi: 10.21124/AJERPK.2020.90.99

2. Whiting DR, Guariguata L, Weil C, Shaw J. IDF diabetes atlas: global estimates of the prevalence of diabetes for 2011 and 2030. Diabetes Res Clin Pract. 2011; 94(3): 311-321. doi: 10.1016/j.diabres.2011.10.029

3. Jamil K, Kakarala KK, Maturi R. Outbreaks of Severe Acute Respiratory Syndrome Coronavirus-2 (SARS-CoV-2) in Comorbid Patients: Review article: Applied Medical Research. 2021; 8(1): 1-3 doi: 10.5455/ amr.20211027ISSN

4. Jamil K, Tantray JA, Syed R. Implications of SARS-CoV-2 (COVID-19) pandemic and fatal outcomes of patients with Lifestyle disorders and NCDs. ScienceDocuments. 2021; 1(3):doi: 10.32954/synsdocs.2020.001.08

5. Rubino F, Amiel SA, Zimmet $P$, et al. New-Onset Diabetes in Covid-19. $N$ Engl J Med. 2020; 383(8): 789-790. doi: 10.1056/NEJMc2018688

6. Huang $C$, Wang $Y, L i X$, et al. Clinical features of patients infected with 2019 novel corona virus in Wuhan, China. Lancet. 2020; 395: 497-506. doi: 10.1016/S0140-6736(20)30183-5

7. Guan WJ, Liang WH, Zhao Y, et al. Comorbidity and its impact on 1590 patients with Covid-19 in China: A Nationwide Analysis. Eur Respir J. 2020; 55(5): 2000547. doi: 10.1183/13993003.00547-2020

8. Hoffmann M, Kleine-Weber H, Schroeder S, et al. SARS-CoV-2 Cell Entry Depends on ACE2 and TMPRSS2 and Is Blocked by a Clinically Proven Protease Inhibitor. Cell. 2020; 181(2): 271-80. doi: 10.1016/j.cell.2020.02.052

9. Unsworth R, Wallace S, Oliver NS, et al. New-Onset Type 1 Diabetes in Children During COVID-19: Multicenter Regional Findings in the U.K. Diabetes Care. 2020; 43(11): 170-171. doi: 10.2337/dc20-1551

10. Müller JA, Groß R, Conzelmann C, et al. SARS-CoV-2 infects and replicates in cells of the human endocrine and exocrine pancreas. Nat Metab. 2021; 3(2): 149-65. doi: 10.1038/s42255-021-00347-1

11. Buckland MS, Galloway JB, Fhogartaigh CN, et al. Treatment of COVID-19 with remdesivir in the absence of humoral immunity: a case report. Nat Commun. 2020; 11: 6385. doi: 10.1038/s41467-020-19761-2

12. Wu CT, Lidsky PV, Xiao $Y$, et al. SARS-CoV-2 infects human pancreatic $\beta$ cells and elicits $\beta$ cell impairment. Cell Metab. 2021; 33(8): 1565-1576. doi: 10.1016/j.cmet.2021.05.013

13. Varghese E, Samuel SM, Liskova A, Kubatka P, Büsselberg D. Diabetes and coronavirus (SARS-CoV-2): Molecular mechanism of Metformin intervention and the scientific basis of drug repurposing. PLoS Pathog. 2021; 17(6): e1009634. doi: 10.1371/journal.ppat.1009634

14. Ni W, Yang $X$, Yang $D$, et al. Role of angiotensin-converting enzyme 2 (ACE2) in COVID-19. Crit Care. 2020; 24(1): 422. doi: 10.1186/s13054020-03120-0

15. Wu $C, Y e D$, Mullick $A E$, et al. Effects of Renin-Angiotensin Inhibition on ACE2 and TMPRSS2 Expression: Insights into COVID-19. bioRxiv. 2020; doi: $10.1101 / 2020.06 .08 .137331$

16. Yang J, Petitjean SJL, Koehler $\mathrm{M}$, et al. Molecular interaction and inhibition of SARS-CoV-2 binding to the ACE2 receptor. Nat Commun. 2020; 11(1): 4541. doi: 10.1038/s41467-020-18319-6

17. He L, Mäe MA, Muhl L, et al. Pericyte-specific vascular expression of SARS-CoV-2 receptor ACE2-implications for microvascular inflammation and hypercoagulopathy in COVID-19. bioRxiv. 2020; doi: 10.1101/2020.05.11.088500
18. Scialo F, Daniele A, Amato F, et al. ACE2: The Major Cell Entry Receptor for SARS-CoV-2. Lung. 2020; 198(6): 867-877. doi: 10.1007/s00408-020$00408-4$

19. Ribes $A$, Vardon-Bounes $F$, Mémier $V$, et al. Thromboembolic events and Covid-19. Adv Biol Regul. 2020; 77. doi: 10.1016/j.jbior.2020.100735

20. Tang N, Li D, Wang $X$, Sun Z. Abnormal coagulation parameters are associated with poor prognosis in patients with novel coronavirus pneumonia. J Thromb Haemost. 2020; 18(4): 844-7. doi: 10.1111/jth.14768

21. Habib Y, Thozhukat S, Tannaz J, Amirhossein S. The impact of Diabetes Mellitus in COVID-19: A Mechanistic Review of Molecular Interactions. Journal ofDiabetes Research.2020;9.5436832 doi:10.1155/2020/5436832

22. Liao YH, Zheng JQ, Zheng CM, Lu KC, Chao YC. Novel Molecular Evidence Related to COVID-19 in Patients with Diabetes Mellitus. J Clin Med. 2020; 9(12): 3962. doi: $10.3390 / \mathrm{jcm} 9123962$

23. Overbergh L, Gysemans $\mathrm{C}$, Colli ML, et al. SARS-CoV-2 Receptor Angiotensin I-Converting Enzyme Type 2 (ACE2) Is Expressed in Human Pancreatic $\beta$-Cells and in the Human Pancreas Microvasculature. Front Endocrinol Lausanne. 2020; 13(11): 596898. doi: 10.3389/ fendo.2020.596898

24. Chee YJ, Ng SJH, Yeoh E. Diabetic ketoacidosis precipitated by Covid-19 in a patient with newly diagnosed diabetes mellitus. Diabetes Res. Clin Pract. 2020; 164: 108166. doi: 10.1016/j.diabres.2020.108166

25. Yang $L$, Han $Y$, Nilsson-Payant $B E$, et al. A human pluripotent stem cellbased platform to study SARS-CoV-2 tropism and model virus infection in human cells and organoids. Cell Stem Cell. 2020; 27(1): 125-136. doi: 10.1016/j.stem.2020.06.015

26. Steenblock $C$, Richter $S$, Berger I, et al. Viral infiltration of pancreatic islets in patients with COVID-19. Nat Commun. 2021; 12(1): 3534. doi: $10.1038 / \mathrm{s} 41467-021-23886-3$

27. Heaney Al, Griffin GD, Simon EL. Newly diagnosed diabetes and diabetic ketoacidosis precipitated by COVID-19 infection. Am J Emerg Med. 2020; 38(11): 2491-2494. doi: 10.1016/j.ajem.2020.05.114

28. Boddu SK, Aurangabadkar G, Kuchay MS. New onset diabetes, type 1 diabetes and COVID-19. Diabetes Metab Syndr. 2020; 14(6): 2211-2217. doi: 10.1016/j.dsx.2020.11.012

29. Alsadhan I, et al. Diabetic ketoacidosis precipitated by Coronavirus disease 2019 infection: case series. Curr Ther Res Clin Exp. 2020; 93:100609. doi: 10.1016/j.curtheres.2020.100609

30. Accili D. Can COVID-19 cause diabetes? Nat Metab. 2021; 3(2): 123-125 doi: $10.1038 / s 42255-020-00339-7$

31. Zhang Z, Liew CW, Handy $D E$, et al. High glucose inhibits glucose-6phosphate dehydrogenase, leading to increased oxidative stress and $\beta$-cell apoptosis. FASEB J. 2010; 24(5): 1497-1505. doi: 10.1096/fj.09136572

32. Vaduganathan $M$, Vardeny $O$, Michel $T$, et al. Renin-angiotensinaldosterone system inhibitors in patients with Covid-19. N Engl J Med. 2020; 382(17): 1653-1659. doi: 10.1056/NEJMsr2005760

33. Codo AC, Davanzo GG, Monteiro LB, et al, Elevated Glucose Levels Favor SARS-CoV-2 Infection and Monocyte Response through a HIF-1 $\alpha$ / Glycolysis Dependent Axis. Cell Metab. 2020; 32(3): 437-446. e5 doi: 10.1016/j.cmet.2020.07.007

34. Wu CT, Lidsky PV, Xiao $Y$, et al. SARS-CoV-2 infects human pancreatic $\beta$ cells and elicits $\beta$ cell impairment. Cell Metab. 2021; 33(8): 1565-1576. doi: 10.1016/j.cmet.2021.05.013

35. Tang $X$, Uhl S, Zhang T, et al. SARS-CoV-2 infection induces beta cell transdifferentiation. Cell Metab. 2021; 33(8): 1577-1591.e7. doi: 10.1016/j.cmet.2021.05.015

36. Daly JL, Simonetti B, Klein $\mathrm{K}$, et al. Neuropilin-1 is a host factor for SARSCoV-2 infection. Science. 2020; 370: 861-865. doi: 10.1126/science. abd3072 
37. Cantuti-Castelvetri $\mathrm{L}$, et al. Neuropilin-1 facilitates SARS-CoV-2 cell entry and infectivity. Science. 2020; 370(6518): 856-860. doi: 10.1126/ science.abd2985

38. Francesco R, Paul Z, George A, et al. New-Onset Diabetes in Covid-19. N Engl J Med. 2020; 383(3): 789-790. doi: 10.1056/NEJMc2018688

39. Hoffmann M, Kleinen WH, Schroeder S, et al. SARS-CoV-2 Cell Entry Depends on ACE2 and TMPRSS2 and Is Blocked by a Clinically Proven Protease Inhibitor. Cell. 2020; 181(2): 271-280. doi: 10.1016/j. cell.2020.02.052

40. Lisco G, De Tullio A, Giagulli VA, et al. Hypothesized mechanisms explaining poor prognosis in type 2 diabetes patients with COVID-19: a review. Endocrine. 2020; 70(3): 441-53. doi: 10.1007/s12020-020-02444-9
41. Mehta P, McAuley DF, Brown M, et al. COVID-19: consider cytokine storm syndromes and immunosuppression. Lancet. 2020; 395(10299): 1033-1034. doi: 10.1016/S0140-6736(20)30628-0

42. Guo W, Li M, Dong $Y$, et al. Diabetes is a risk factor for the progression and prognosis of COVID-19. Diabetes Metab Res/Rev. 2020; 36(7): e3319. doi: $10.1002 /$ dmrr.3319

43. Anderson MR, Geleris J, Anderson DR, et al. Body Mass Index and Risk for Intubation or Death in SARS-CoV-2 Infection: A Retrospective Cohort Study. Ann Inter Med. 2020; 173(10): 782-790. doi: 10.7326/M20-3214 